\title{
Biografía
}

\section{Dr. Solón Núñez Frutos}

El Doctor Solón Núñez es un ejemplo de que un ser humano que posea ideales claros puede lograr prácticamente cualquier objetivo, y su biografía sirve como modelo para que nadie se sienta nunca abatido por las duras experiencias de la vida. Conocer los logros de ese pequeño gran hombre es un compromiso de todo costarricense.

Solón Núñez nació el 29 de abril de 1881, en una familia pobre, y cuando cursaba el segundo grado murió su madre y poco después su padre, por lo que sus cuatro hermanos y él fueron distribuidos entre los familiares. A Solón le tocó vivir en Desamparados y ser criado por una tía materna y su esposo. Todo haría pensar que aquel niño descalzo se convertiría en otro campesino más de la Costa Rica del siglo XIX.

Contrario a las costumbres de la época, cuando se utilizaba a los jóvenes para ayudar a sus mayores en el trabajo, Solón terminó la enseñanza primaria, y para hacerlo debió viajar los dos últimos años a pie, entre Desamparados y San José, pues la escuela local había cerrado el cuarto y quinto grados, por falta de fondos. Al finalizar sus estudios primarios, Solón fue el alumno más destacado de su promoción, y al año siguiente, gracias a una beca, ingresó al Liceo de Costa Rica, donde demostró una vez más su inteligencia y dedicación. En aquellos años debía caminar con los zapatos en la mano, no solo para no gastarlos, sino para evitar que se ensuciaran en la travesía diaria de diez kilómetros.

$\mathrm{Al}$ terminar el colegio se graduó de maestro, y tanto él como sus parientes debieron sentirse orgullosos cuando consiguió una plaza de docente de primer grado en Naranjo, siendo pronto promocionado a Mata Redonda, por pedido suyo, pues deseaba estar cerca de la capital para estudiar Derecho. El 20 de diciembre de 1906 se casó con su novia, la señorita Oliva Rojas Solórzano, con quien compartiría su vida por más de 60 años; juntos tendrían dos hijos, una mujer y un varón, que les darían cuatro nietos, dos de los cuales siguieron sus pasos de médico y cirujano.

Se entiende con claridad que un costarricense pobre jamás podría llegar a ser médico a principios del siglo XX. Para realizar esos estudios era necesario salir del país y dirigirse preferiblemente a Europa; algo imposible para cualquier persona de escasos recursos.
Sin embargo, la fortuna lo favoreció y se ganó la lotería. Bien podía haber dilapidado el dinero, comprarse los lujos que nunca había tenido, o terminar sus estudios de Derecho, pero él, como maestro que había visto de cerca la pobreza y las calamidades del pueblo costarricense, se regocijó con el premio y vio la posibilidad de cumplir su anhelo secreto. Ante el asombro de sus familiares y amigos, comunicó que usaría el dinero para estudiar medicina.

Lamentablemente, lo único que poseía era la cantidad ganada, que debería alcanzarle para todos sus años de estudio.

Imposibilitado para llevarse a su esposa, la dejó en Costa Rica mientras él se marchó a Europa en barco, descubriendo que la Facultad de Medicina de Ginebra resultaba la más adecuada a su rígido y lacónico presupuesto.

En Ginebra conoció a quien sería su benefactor y amigo el futuro Dr. Ricardo Moreno Cañas. Debido a la gran sensibilidad de ambos para ayudar a sus semejantes, se marcharon al frente durante la Primera Guerra Mundial, y se asentaron en el hospital Saint Louis de Lyon para atender a los ejércitos franceses. Dado este épico acto de altruismo, el gobierno francés le concedería Las Palmas Académicas en 1933.

A su regreso al país, después de haberse graduado en 1915 con excelentes calificaciones, y de ser reconocida su capacidad por los profesores ginebrinos, fue recibido con grandes manifestaciones de júbilo por sus paisanos de Desamparados. Posiblemente era la primera persona de escasos recursos que se hacía médico en esa comunidad.

Al establecer su consultorio privado, empezó a darse cuenta de las grandes calamidades que aquejaban a los costarricenses y de la dificultad de muchos para obtener atención médica. Por eso, y ante la posibilidad de recibir una beca de la Fundación Rockefeller, que estaba combatiendo en Latinoamérica las enfermedades parasitarias que diezmaban a la población, viajó a Estados Unidos para estudiar Salud Pública. 
De nuevo en su tierra, y conocedor de los problemas de los costarricenses, decidió emprender una epopeya contra las enfermedades parasitarias y se entregó por completo a la salud pública, llegando a convertirse en el primer higienista nacional, y en uno de los principales de América Latina.

En 1922 fue nombrado Subsecretario de Estado en el Despacho de Higiene, desde donde comenzó a impulsar y a defender con calor ante la Asamblea Legislativa, la creación de un Ministerio de Salubridad, adelantándose mucho a la época, ya que en aquel tiempo solo Cuba contaba con un Ministerio de Estado semejante.

En 1927 el doctor Núñez fue nombrado el primer ministro de Salubridad Pública, cargo que ocuparía hasta 1936 y luego también entre 1943 y 1948.

Desde esa cartera realizó una labor incansable, pues la legislación nacional era casi inexistente, y aunado a eso debía vencer toda una cantidad de conflictos enormes.

Con un entusiasmo impresionante comenzó a luchar contra el cansancio, nombre con el cual se conocía la anquilostomiasis intestinal, y obtuvo de la Fundación Rockefeller enorme cantidad de zapatos para calzar a la población rural costarricense. Al mismo tiempo, empezó una campaña nacional de letrinización, debiendo para eso visitar todos los rincones del país y convencer a la gente de que cambiara los pozos negros por retretes apropiados.

Como maestro, preocupado por la niñez desde hacía años, dio inicio a programas para disminuir la mortalidad infantil, y estableció en 1920 clínicas infantiles y servicios prenatales, creando al mismo tiempo un Departamento de Profilaxis Dental y dos plazas de médicos oculistas para atender a los escolares de San José, Heredia y Alajuela, a quienes se les suministraban anteojos en forma gratuita, si eran pobres. En 1935 consiguió una partida para suministrar leche a los niños de escasos recursos, y conocedor de que los maestros eran los responsables de los niños, decretó tratamiento médico gratuito para los docentes y la donación -sin costo alguno- de quinina a escolares, maestros y personal del Resguardo. La Asociación Costarricense de Pediatría debería honrarlo como el primer costarricense preocupado con ahínco por la niñez nacional.

Otra de sus cruzadas fue la lucha contra la tuberculosis. En 1931 emitió un Decreto para reformar el Sanatorio para Tuberculosos, le dio el nombre de Sanatorio Dr. Carlos Durán y consideró la enfermedad de declaración obligatoria.

Uno de sus grandes logros fue la creación del Código de Higiene, orgullo nacional que después fue imitado por muchos países. Los proyectos y legislación sanitaria promulgados durante su gestión pública resultaron ser innovadores, no solo para entonces, sino que sirvieron como base para la futura concepción de la medicina nacional, tal como la Escuela de Inspectores de Sanidad. La enseñanza de los buenos hábitos de higiene formó también parte fundamental de la educación a la población costarricense.

El doctor Núñez luchó enconadamente contra el paludismo y las enfermedades venéreas, creando clínicas gratuitas y hablando por primera vez en el país de educación sexual. También en el campo de la lepra fue innovador, y su trabajo resultó visionario, al autorizar la visita de los familiares a los enfermos internados en el Sanatorio de Las Mercedes, y la visita de algunos leprosos a sus casas.

También la campaña de vacunación fue puesta en primer lugar durante su gestión, y en 1929 empezó una profilaxis masiva contra la tifoidea.

El doctor Núñez murió en San José el 3 de agosto de 1975, a los 94 años de edad, y ese mismo año la Caja Costarricense de Seguro Social creó la Clínica Solón Núñez, en Hatillo, y en 1978, la Asamblea Legislativa lo declaró Benemérito de la Patria, máximo galardón al que puede aspirar un costarricense. La Dirección Nacional de Comunicaciones (CORTEL) lo inmortalizó en 1992 en un sello de correo (Figura 1).

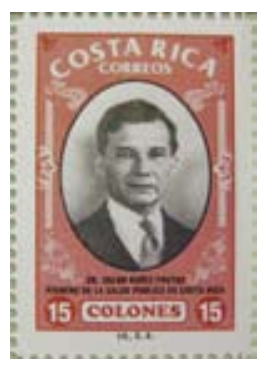

Figura 1. Sello Postal Dr. Solón Nuñez. Cortesía: Museo Filatélico, Edificio Central de Correos de Costa Rica S.A.

El trabajo del doctor Núñez fue fecundo, intenso y desinteresado; debió luchar contra la ignorancia e incomprensión de muchas personas y consiguió todos sus logros con un presupuesto exiguo.

Es preciso señalar que el doctor Núñez tuvo otras cualidades a la par de su labor de higienista. Sus escritos literarios y periodísticos lo revelan como un gran escritor, y sería bueno que los médicos jóvenes leyeran sus publicaciones literario-científicas, como Jesús y Tolstoi; Juan Montalvo; El doctor Clodomiro Picado ha muerto...; La tosferina, o La influenza epidémica, de actualidad en estos años; Mi catecismo higiénico; Unos días en Lima; La leche, el mejor alimento; Las bibliotecas médicas de los hospitales; La socialización de la Medicina el nuevo rico y el sabio pobre, y muchos otros. 
Su capacidad oratoria era tan espectacular, que los foros de Latinoamérica, Europa y Estados Unidos reconocieron múltiples veces su dialéctica en sus discursos, tanto en español, inglés, o en su querido francés, idioma que hablaba siempre con sus íntimos amigos los doctores Moreno Cañas, Clorito Picado y Calderón Guardia, con quien compartió la preocupación por atender en forma gratuita a la población costarricense enferma. El doctor Núñez llenó de gloria a Costa Rica en cada una de sus salidas al extranjero, y sus opiniones eran tomadas en cuenta por las autoridades sanitarias de los países que visitaba, convirtiéndose sin lugar a dudas en un higienista universal.

Debe quedar constancia de que fue una persona de costumbres intachables, un padre y esposo ejemplar, que cultivó y se regocijó con todas las formas del arte. Su entusiasmo, empeño y tenacidad, unidos a su vocación de maestro y de médico, fueron quizá la levadura para hacer de él un ser extraordinario.

Recientemente, la Facultad de Medicina de la Universidad de Costa Rica colocó un busto suyo, a la entrada de su edificio principal en la Ciudad Universitaria Rodrigo Facio.

Rafael Jiménez Bonilla

Miembro del Comité Editorial AMC

\section{Referencias}

1. Paulo Schilling, El Imperio Rockefeller: América Latina. Tierra Nueva, Uruguay. 1970 7-12.

2. Ministerio de Salubridad Pública. Homenaje al Dr. Solón Núñez Frutos. 1963 San José, Costa Rica.

3. Colegio de Médicos y Cirujanos de Costa Rica. 1958, Homenaje al doctor Solón Núñez Frutos.

4. Murillo Gabriela, Galván Brayan, Solano Karen. Seminario de Realidad Nacional I. 2001, Universidad de Costa Rica.

5. Frutos Verdesia, Juan Bautista. Doctor Solón Núñez Frutos. Departamento de Publicaciones del Ministerio de Cultura Juventud y Deportes. 1979 San José, Costa Rica. 